\title{
Antibiotic prescribing practices by dentists: a review
}

This article was published in the following Dove Press journal:

Therapeutics and Clinical Risk Management

19 June 2010

Number of times this article has been viewed

\author{
Najla Saeed Dar-Odeh' \\ Osama Abdalla Abu- \\ Hammad' \\ Mahmoud Khaled Al-Omiri' \\ Ameen Sameh Khraisat' \\ Asem Ata Shehabi ${ }^{2}$ \\ 'Faculty of Dentistry, University \\ of Jordan, Amman, Jordan; ${ }^{2}$ Faculty \\ of Medicine, University of Jordan, \\ Amman, Jordan
}

\begin{abstract}
Antibiotics are prescribed by dentists for treatment as well as prevention of infection. Indications for the use of systemic antibiotics in dentistry are limited, since most dental and periodontal diseases are best managed by operative intervention and oral hygiene measures. However, the literature provides evidence of inadequate prescribing practices by dentists, due to a number of factors ranging from inadequate knowledge to social factors. Here we review studies that investigated the pattern of antibiotic use by dentists worldwide. The main defects in the knowledge of antibiotic prescribing are outlined. The main conclusion is that, unfortunately, the prescribing practices of dentists are inadequate and this is manifested by over-prescribing. Recommendations to improve antibiotic prescribing practices are presented in an attempt to curb the increasing incidence of antibiotic resistance and other side effects of antibiotic abuse.
\end{abstract}

Keywords: over-prescribing, antimicrobial resistance, recommended practice, penicillin

\section{Introduction}

Dentists prescribe medications for the management of a number of oral conditions, mainly orofacial infections. ${ }^{1}$ Since most human orofacial infections originate from odontogenic infections, ${ }^{2}$ the prescribing of antibiotics by dental practitioners has become an important aspect of dental practice. For this reason, antibiotics account for the vast majority of medicines prescribed by dentists. ${ }^{3}$ Dentists prescribe between $7 \%$ and $11 \%$ of all common antibiotics (betalactams, macrolides, tetracyclines, clindamycin, metronidazole). ${ }^{4}$ In the UK, for instance, dentists accounted for $7 \%$ of all community prescriptions of antimicrobials. ${ }^{5}$ On the other hand, the National Center for Disease Control and Prevention estimate that approximately one-third of all outpatient antibiotic prescriptions are unnecessary. ${ }^{6}$

Antibiotic prescribing may be associated with unfavorable side effects ranging from gastrointestinal disturbances to fatal anaphylactic shock and development of resistance. The increasing resistance problems of recent years are probably related to over- or mis-use of broad-spectrum agents such as cephalosporins and fluoro-quinolones. ${ }^{7} \mathrm{We}$ have now entered an era where some bacterial species are resistant to the full range of antibiotics presently available, with the methicillin-resistant Staphylococcus aureus being the most widely known example of extensive resistance. ${ }^{3}$

These serious complications associated with antibiotics use have encouraged studies investigating antibiotic prescribing practices of dentists. ${ }^{8-23}$

The PubMed database was searched in February 2010, and search criteria included: antibiotic, dentist, and prescribing. Searches were limited to human studies published 
in English. Over 400 references were retrieved; 33 of them investigated antibiotic prescribing by dentists. These references were reviewed to evaluate the therapeutic and prophylactic antibiotic prescribing practices of dentists with a focus on indications of antibiotics, type of antibiotic prescribed, and the duration of prescription.

\section{Therapeutic antibiotic prescribing by dentists}

Most oral diseases presented to the dentist are primarily inflammatory conditions that are associated with pain. These inflammatory conditions and their associated clinical features are shown in Table 1. A considerable percentage of dental pain originates from acute and chronic infections of pulpal origin, which necessitates operative intervention, ${ }^{24}$ rather than antibiotics. Non-indicated clinical cases for antibiotic use include acute periapical infection, dry socket, and pulpitis. ${ }^{15}$ Chronic inflammatory periodontal conditions are also not indicated for antibiotics; systemic antimicrobials should only be used in acute periodontal conditions where drainage or debridement is impossible, where there is local spread of the infection or where systemic upset has occurred. ${ }^{10}$

Data reported from different countries indicate differences in dentists' knowledge of clinical situations indicated for antibiotics. Almost half or more of the dentists investigated in England, ${ }^{8}$ Kuwait, ${ }^{15}$ and Turkey ${ }^{19}$ would prescribe for dry socket. Another non-indicated condition is localized swelling, which was also among the conditions for which antibiotics were prescribed in Norway, ${ }^{7}$ South Australia, ${ }^{14}$ Kuwait, ${ }^{15}$ and England. ${ }^{25}$ On the other hand, the figures for England show that admissions for 'drainage of an abscess related to tooth has doubled from just under 800 in 1998 to almost 1600 in $2006 .^{3}$

More common dental infections present in the form of pulpitis and periapical periodontitis, which require only operative measures like fillings, root canal therapy, or extraction if the tooth is not restorable. Unfortunately, dentists still prescribe antibiotics for this condition. ${ }^{8,11,15,17}$, 19,23,26,27 A distressing finding was that a number of dentists prescribe antibiotics for viral infections like herpes simplex virus-1 infections. ${ }^{11}$

Clinical situations that require antibiotic therapy on empirical basis are limited, and they include oral infection accompanied by elevated body temperature and evidence of systemic spread like lymphadenopathy and trismus. ${ }^{6}$ Facial cellulitis that may or may not be associated with dysphagia, ${ }^{15}$ is a serious disease that should be treated by antibiotics promptly because of the possibility of infection spread via lymph and blood circulation, with development of septicemia.

There are also a limited number of localized oral lesions that are indicated for antibiotic use and these include periodontal abscess, acute necrotizing ulcerative gingivitis, and pericoronitis. $^{15}$

Another aspect of antibiotic over-prescribing is prescribing based on non-clinical factors. Patient's expectation of

Table I Orofacial painful/inflammatory conditions that may be encountered in dental practice and their important features

\begin{tabular}{|c|c|}
\hline Inflammatory condition & Important features \\
\hline Reversible pulpitis & $\begin{array}{l}\text { Pain is poorly localized, of very short duration and may outlast the stimulus. Tooth is not tender to } \\
\text { percussion. Normal radiographic appearance. }\end{array}$ \\
\hline Irreversible pulpitis & $\begin{array}{l}\text { Spontaneous attacks of pain ranging from few seconds to several hours. Pain is elicited by hot or } \\
\text { cold applications. In its final stages, it is elicited by hot applications and relieved by cold applications. } \\
\text { Pain initially is not localized unless the periodontal ligament (PL) has become involved, which makes } \\
\text { the tooth tender to percussion and makes the PL appear widened on radiographs. }\end{array}$ \\
\hline Acute periapical periodontitis & Pain is spontaneous, aggravated by biting, and related to a non-vital tooth. \\
\hline Lateral periodontal abscess & $\begin{array}{l}\text { Affected tooth is associated with swollen gingiva, sensitive to percussion, mobile and vital. Pain is } \\
\text { persistent. }\end{array}$ \\
\hline Periodontitis & Pain is localized, dull, with tenderness of associated teeth. \\
\hline Pericoronitis & $\begin{array}{l}\text { Spontaneous pain, worse on biting. There are visible signs of inflammation of the operculum. May } \\
\text { be associated with trismus, lymphadenopathy, and fever. }\end{array}$ \\
\hline Cellulitis & $\begin{array}{l}\text { Swelling, tenderness, and erythema of the affected part of the face, with lymphadenopathy. The } \\
\text { affected tooth is tender. May be associated with a dental abscess. }\end{array}$ \\
\hline Dental hypersensitivity & Pain is sharp, of short duration, and initiated by thermal stimuli and sweets. \\
\hline Cracked tooth & Pain is initiated by thermal stimuli, worse on biting, and difficult to diagnose. \\
\hline Acute necrotizing gingivitis & $\begin{array}{l}\text { Bleeding gums with soreness and ulceration of interdental papillae. Associated with halitosis and } \\
\text { sometimes fever. }\end{array}$ \\
\hline Bacterial sialadenitis & $\begin{array}{l}\text { Affected salivary gland is swollen, tender, and painful especially at meal times. May be associated } \\
\text { with trismus, fever, and lymphadenopathy. }\end{array}$ \\
\hline
\end{tabular}


an antibiotic prescription, convenience, and demand necessitated by the social background of the patients are considered unscientific reasons for antibiotic prescription. Whereas English and Scottish dentists would not prescribe for nonclinical factors, ${ }^{25}$ dentists in the Eastern Mediterranean region have shown a tendency to prescribe on a patient's demand or socially, especially when short of time..$^{15,17}$

The most commonly used antibiotic in dental practice, penicillins in general, were found to be the most commonly prescribed antibiotics by dentists, ${ }^{16,17,20}$ the most popular one being amoxicillin, ${ }^{8,9,16,18,21,22}$ followed by penicillin $\mathrm{V},{ }^{11,12,23}$ metronidazole, ${ }^{8,9}$ and amoxicillin and clavulanate..$^{28}$

Penicillin is still the gold standard in treating dental infections. ${ }^{6}$ Among the group of penicillins, penicillin $\mathrm{V}$, amoxicillin, ${ }^{29}$ and amoxicillin and clavulanate ${ }^{30}$ have been advocated for the treatment of odontogenic infections. Kuriyama et al found no difference in clinical outcome between penicillin V, amoxicillin, or amoxicillin and clavulanate. ${ }^{31}$

Frequency of prescribing is usually mentioned in the known resources for antibiotic prescribing, ${ }^{32}$ whereas duration of treatment recommended in therapeutic guidelines is most commonly based on expert opinion. ${ }^{33}$ A survey in Canada found that the average duration of antibiotic use prescribed by dentists is 6.92 days. ${ }^{13}$ Another survey in the USA found that endodontists prescribe antibiotic use for an average of 7.58 days. ${ }^{23}$ Recent studies on the attitudes of dentists in the Eastern Mediterranean region showed that dentists preferred to prescribe a lower dosage of an antibiotic over a longer period. ${ }^{15,18}$

In recent years, more attention has been given to short courses. Rubenstein explains that short-course antibiotic therapy requires that antibiotics have certain characteristics, such as: rapid onset of action, bactericidal activity, lack of propensity to induce resistant mutants, easy penetrability into tissues, activity against non-dividing bacteria, not being affected by adverse infection conditions (low $\mathrm{pH}$, anaerobiasis, presence of pus, etc.), administration at an optimal dose, and optimal dosing regimen. ${ }^{33}$ A two-dose, 3-gm regimen of amoxicillin has been shown to be effective in certain situations. ${ }^{34}$ On the other hand, oral antibiotic use for 2 or 3 days has been advocated for the treatment of acute dentoalveolar infections, and in doses recommended by the British National Formulary (BNF) ${ }^{24}$ Indeed, in some studies, patients improved after 2 or 3 days of antibiotic therapy. ${ }^{31,35-37}$ In general, reducing the frequency of antibiotic intake (without compromising the dose) has yielded improved results: a twice-daily dosage of amoxicillin/clavulanate had several advantages over the three times-daily dosage, including increased convenience, improved compliance, and improved tolerability. ${ }^{38,39}$

Short courses are preferred to long courses particularly when treating children, since children's compliance with conventional courses is poor. ${ }^{40} \mathrm{~A}$ false conception about the use of antibiotics is that antibiotics should be used for a certain number of days to 'kill the resistant strains' as the vast majority of strains acquire resistance via transposable elements that are preferentially transferred when antibiotics are used in sub-therapeutic doses or for long durations. ${ }^{41}$

In summary, antibiotics should be prescribed at the correct frequency, dose, and duration so that the minimal inhibitory concentration is exceeded, and so that side effects and the selection of resistant bacteria are prevented. ${ }^{8}$ Prolonged courses of antibiotics destroy the commensal flora. ${ }^{38}$ In addition, longer durations of up to 21 days may result in the selection of resistant strains and a reduction in the ability of the oral flora to resist the colonization by harmful micro-organisms that are not normal residents, ${ }^{42}$ leading to superimposed infections by multi-resistant bacteria and yeasts. ${ }^{15}$

\section{Prophylactic antibiotic prescribing}

Prophylactic antibiotics, taken prior to a number of dental procedures, have been advocated to reduce the likelihood of postoperative local complications, like infection, dry socket, or serious systemic complications like infective endocarditis. The evidence for antibiotics acting to prevent infection from surgical wounds in the mouth is poor to non-existent, ${ }^{14}$ indicating that preoperative parenteral antibiotic prophylaxis for routine third molar surgery in medically fit patients is unwarranted. ${ }^{43,44}$ It was also found that a single dose of metronidazole was ineffective in preventing the development of dry socket. ${ }^{45}$ For most dentoalveolar surgical procedures in fit, non-medically compromised patients, antibiotic prophylaxis is not required or recommended. ${ }^{46}$

In the case of bacterial endocarditis (IE), the absolute risk rate after dental treatment, even in at-risk patients, is considered very low. ${ }^{41}$ This is consistent with recent guidelines from the British Society for Antimicrobial Chemotherapy, ${ }^{47}$ and the American Heart Association, ${ }^{48}$ which recommend that only patients in the high risk category require cover. The basis for this recommendation is:

- There is no consistent association between having an intervention, dental or non-dental, and the development of IE.

- Regular tooth brushing almost certainly presents a greater risk of IE than a single dental procedure because of repetitive exposure to bacteremia with oral flora. 
- The clinical effectiveness of antibiotic prophylaxis is not proven.

- Antibiotic prophylaxis against IE for dental procedures may lead to a greater number of deaths through fatal anaphylaxis than would a strategy of no antibiotic prophylaxis. Nor is antibiotic prophylaxis against IE cost effective. ${ }^{49}$

Most studies on prophylactic antibiotic use were carried out in developed countries, ${ }^{8,9,11,13,14}$ and the results generally indicated that dentists have a good knowledge of prescribing.

The few studies done in developing countries ${ }^{15,17}$ reported that abuse of prophylactic antibiotics was to prevent postoperative infection following surgical dental manipulations ${ }^{15}$ or to cover either a defect in aseptic clinical technique or improperly sterilized equipment; thus, a 'just in case' principle is practiced. ${ }^{17}$

\section{Recommendations}

Recommended treatment modalities for common inflammatory oral conditions are shown in Figure 1.

Drainage is the recommended treatment for periapical periodontitis and for localized dentoalveolar abscess, with incisional drainage rather than via the root canal preferred. ${ }^{31}$

Empirical antibiotic therapy and drainage are recommended for more severe infections such as facial cellulitis, pericoronitis, lateral periodontal abscess, and necrotizing ulcerative gingivitis.

The type of antibiotic chosen and its dosing regimen are dependent upon the severity of infection and the predominant type of causative bacteria.

According to the BNF, amoxicillin is recommended for dental infections in doses ranging from $250 \mathrm{mg}$ to $500 \mathrm{mg}$, every 8 hours. ${ }^{50}$ The use of $3 \mathrm{~g}$ amoxicillin repeated after 8 hours is also mentioned, as a short course of oral therapy. ${ }^{50}$ Another antibiotic that is also recommended by the BNF is co-amoxiclav, which can be used in doses ranging from $375 \mathrm{mg}$ to $625 \mathrm{mg}$ every 8 hours. ${ }^{51}$ In patients allergic to penicillin, clindamycin can be used in doses ranging from $150 \mathrm{mg}$ to $450 \mathrm{mg}$ every 6 hours. ${ }^{52}$ Another option for penicillin-allergic patients (as recommended by the BNF) is metronidazole, which can be used in a dose of $200 \mathrm{mg}$ every 8 hours for 3-7 days. ${ }^{53}$

For severe odontogenic infections, higher doses of a broad-spectrum antibiotic may be required. Lewis et al have shown that only $5 \%$ of the main isolates from dental abscesses are resistant to amoxicillin/clavulinic acid. ${ }^{54}$ A more recent study found that bacteria associated with endodontic infections are completely susceptible to amoxicillin/ clavulinic acid..$^{55}$ Furthermore, some researchers observed that amoxicillin/clavulinic acid and clindamycin are the only orally administered antimicrobials with adequate pharmacokinetic/pharmacodynamic properties to be effective against the most commonly isolated oral pathogens for the treatment of orofacial infections. ${ }^{39}$ When amoxicillin/clavulinic acid is used, a dosing regimen of $1 \mathrm{~g}$ twice daily provides a successful clinical outcome, better patient convenience and compliance, and less gastrointestinal upset owing to the minimizing of the clavulinic acid dose ${ }^{39}$ As mentioned previously, patients can be seen after 2 or 3 days to determine whether treatment should be stopped or continued.

Patients who are allergic to penicillin should benefit from clindamycin; it is active against some oral anaerobes and facultative bacteria, and has the advantage of good bone penetration. However, increasing the dose may increase the possibility of serious side effects such as pseudomembranous colitis, ${ }^{56-58}$ Sweet's syndrome, ${ }^{59}$ and neutropenia. ${ }^{60}$

Infections in which anaerobic bacteria are implicated (such as pericoronitis, periodontal abscess and necrotizing ulcerative gingivitis) are better treated with metronidazole; the best dosage regimen in terms of pharmacodynamic/ pharmacokinetic aspect is $250 \mathrm{mg}$ every 8 hours. ${ }^{39}$

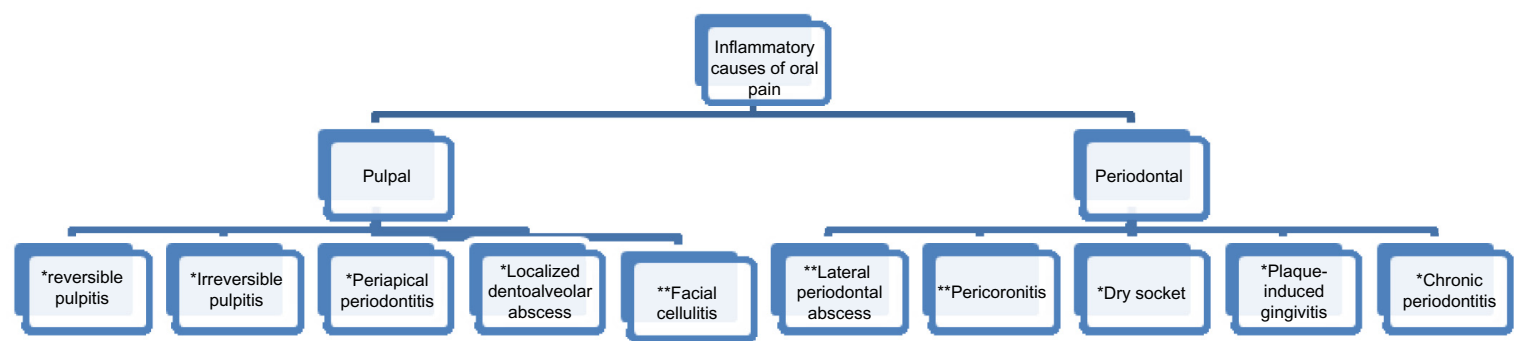

Figure I Recommended treatment modalities for common inflammatory oral lesions.

Notes: *Operative intervention is needed, like filling, root canal treatment, local irrigation, incisional drainage, and oral hygiene measures. ${ }^{*}$ Empirical antibiotic prescribing is needed as an initial treatment. Operative intervention(s) may be initiated on the same visit or later. Oral hygiene measures are mandatory. 
Other inflammatory/painful oral conditions such as cracked tooth, dentine hypersensitivity, and bacterial sialadentitis are outside the scope of this review and their management is thoroughly explained in specialized references.

In addition to the proper dosing regimens and professionally responsible prescribing practices, the general public needs to be educated about the importance of restricting the use of antibiotics to only cases of severe infection. Patients have become accustomed to being given an antibiotic for a range of medical complaints. Unfortunately, patients presenting at dental surgeries also routinely expect an antibiotic for the treatment of 'toothache'. ${ }^{3}$

Dental patients not only pressure their dentist to get an antibiotic prescription, they also self-medicate. Selfmedication with antibiotics was found to be alarmingly high in some developing countries. ${ }^{61-64}$ Also in Europe, self-prescription of antibiotics was reported, particularly in eastern and southern parts..$^{65,66}$

In conclusion, prescribing practices of dentists can be improved by increasing awareness among dental practitioners of the recommended guidelines. Furthermore, the importance of initiating awareness programs among the general public should not be overlooked.

\section{Disclosure}

The authors report no conflicts of interest in this work.

\section{References}

1. Dar-Odeh N, Ryalat S, Shayyab M, Abu-Hammad O. Analysis of clinical records of dental patients attending Jordan University Hospital: documentation of drug prescriptions and local anesthetic injections. Ther Clin Risk Manag. 2008;4(5):1111-1117.

2. Laskin DM, Laskin JL. Odontogenic infections of the head and neck. In: Laskin DM, editor. Oral and maxillofacial surgery. St Louis: Mosby; 1985:219-252.

3. Lewis MA. Why we must reduce dental prescription of antibiotics: European Union Antibiotic Awareness Day. Br Dent J. 2008;205(10):537-538.

4. Cleveland JI, Kohn WC. Antimicrobial resistance and dental care: a CDC perspective. Dent Abstr. 1998;108-110.

5. Sweeney LC, Dave J, Chambers PA, Heritage J. Antibiotic resistance in general dental practice - a cause for concern? JAntimicrob Chemother 2004;53:567-576.

6. Swift JQ, Gulden WS. Antibiotic therapy - managing odontogenic infections. Dent Clin N Am. 2002;46:623-633.

7. Wise R, Hart T, Carrs O, et al. Antimicrobial resistance is a major threat to public health. BMJ. 1998;317:609-610.

8. Palmer NO, Martin MV, Pealing R, Ireland RS. An analysis of antibiotic prescriptions from general dental practitioners in England. JAntimicrob Chemother. 2000;46:1033-1035.

9. Palmer NO, Martin MV, Pealing R, Ireland RS. Paediatric antibiotic prescribing by general dental practitioners in England. Inter J Paediatr Dent. 2001;11:242-248.

10. Addy M, Martin MV. Systemic antimicrobials in the treatment of chronic periodontal diseases: a dilemma. Oral Dis. 2003;9 Suppl 1: $38-44$.
11. Demirbas F, Gjermo PE, and Preus HR. Antibiotic prescribing practices among Norwegian dentists. Acta Odontol Scand. 2006;64(6):355-359.

12. Al-Haroni M, Skaug N. Incidence of antibiotic prescribing in dental practice in Norway and its contribution to national consumption. J Antimicrob Chemother. 2007;59:1161-1166.

13. Epstein JB, Chong S, Le ND. A survey of antibiotic use in dentistry. JAm Dent Assoc. 2000;131(11):1600-1609.

14. Jaunay T, Sambrook P, Goss A. Antibiotic prescribing practices by South Australian general dental practitioners. Aust Dent J. 2000;45(3):179-186.

15. Salako N, Rotimi VO, Adib SM, Al-Mutawa S. Pattern of antibiotic prescription in the management of oral diseases among dentists in Kuwait. J Dent. 2004;32:503-509.

16. Al-Mubarak S, Al-Nowaiser A, Rass MA, et al. Antibiotic prescription and dental practice within Saudi Arabia; the need to reinforce guidelines and implement specialty needs. $J$ Int Acad Periodontol. 2004;6(2):47-55.

17. Al-Haroni M, Skaug N. Knowledge of prescribing antimicrobials among Yemeni general dentists. Acta Odontol Scand. 2006;64(5):274-280.

18. Dar-Odeh NS, Abu-Hammad OA, Khraisat AS, El Maaytah MA, Shehabi A. An analysis of therapeutic, adult antibiotic prescriptions issued by dental practitioners in Jordan. Chemotherapy. 2008;54(1):17-22.

19. O" cek Z, Sahin H, Baksi G, Apaydin S. Development of a rational antibiotic usage course for dentists. Eur J Dent Educ. 2008;12:41-47.

20. Ogunbodede EO, Fatusi OA, Folayan MO, Olayiwola G. Retrospective survey of antibiotic prescriptions in dentistry. J Contemp Dent Pract. 2005;6(2):64-71.

21. Sarkar C, Das B, Baral P. An audit of drug prescribing practices of dentists. Indian J Dent Res. 2004;15(2):58-61.

22. Murti A, Morse Z. Dental antibiotic prescription in Fijian adults. Int Dent J. 2007;57(2):65-70.

23. Yingling NM, Byrne BE, Hartwell GR. Antibiotic use by members of the American Association of Endodontists in the year 2000: report of a national survey. $J$ Endod. 2002;28(5):396-404.

24. Longman LP, Preston AJ, Martin MV, Wilson NHF. Endodontics in the adult patient: the role of antibiotics. J Dent. 2000;28:539-548.

25. Palmer NO, Martin MV, Pealing R, et al. Antibiotic prescribing knowledge of National Health Service general dental practitioners in England and Scotland. J Antimicrob Chemother. 2001;47(2):233-237.

26. Rodriguez-Núñez A, Cisneros-Cabello R, Velasco-Ortega E, Llamas-Carreras JM, Tórres-Lagares D, Segura-Egea JJ. Antibiotic use by members of the Spanish Endodontic Society. $J$ Endod. 2009;35(9):1198-1203.

27. Mainjot A, D'Hoore W, Vanheusden A, Van Nieuwenhuysen JP. Antibiotic prescribing in dental practice in Belgium. Int Endod J. 2009;42(12):1112-1117.

28. Poveda Roda R, Bagan JV, Sanchis Bielsa JM, Carbonell Pastor E. Antibiotic use in dental practice. A review. Med Oral Patol Oral Cir Bucal. 2007;12(3):E186-192.

29. Ellison SJ. The role of phenoxymethylpenicillin, amoxicillin, metronidazole and clindamycin in the management of acute dentoalveolar abscesses - a review. Br Dent J. 2009;206(7):357-362.

30. Farrier JN, Kittur MA, Sugar AW. Necrotising fasciitis of the submandibular region; a complication of odontogenic origin. Br Dent $J$. 2007;202(10):607-609.

31. Kuriyama T, Absi EG, Williams DW, Lewis MA. An outcome audit of the treatment of acute dentoalveolar infection: impact of penicillin resistance. Br Dent J. 2005;198(12):759-763.

32. British Dental Association; British Medical Association; Royal Pharmaceutical Society of Great Britain. Dental Practitioner's Formulary. London UK: British Medical Association and the Royal Pharmaceutical Society of Great Britain; 2006.

33. Rubinstein E. Short antibiotic treatment courses or how short is short? Inter J Antimicrob Agents. 2007;30S:S76-S79.

34. Swift JQ, Gulden WS. Antibiotic therapy - managing odontogenic infections. Dent Clin N Am. 2002;46:623-633. 
35. Lewis MA, McGowan DA, MacFarlane TW. Short-course high-dosage andomized in the treatment of acute dento-alveolar abscess. Br Dent J. 1986;25;161(8):299-302.

36. Paterson SA, Curzon ME. The effect of andomized versus penicillin V in the treatment of acutely abscessed primary teeth. $\mathrm{Br}$ Dent $J$. 1993;19;174(12):443-449.

37. Martin MV, Longman LP, Hill JB, Hardy P. Acute dentoalveolar infections: an investigation of the duration of antibiotic therapy. Br Dent $J$. 1997;23;183(4):135-137.

38. Bax R. Development of a twice daily dosing regimen of amoxicillin/ clavulanate. Int J Antimicrob Agents. 2007;30 Suppl 2:S118-S121.

39. Isla A, Canut A, Gascón AR, Labora A, Ardanza-Trevijano B, Solinís MA, Pedraz JL. Pharmacokinetic/pharmacodynamic evaluation of antimicrobial treatments of orofacial odontogenic infections. Clin Pharmacokinet. 2005;44(3):305-316.

40. Charney E, Bynum R, Eldredge D, et al. How well do patients take oral penicillin? A collaborative study in private practice. Pediatrics. 1967;40(2):188-195.

41. Pallasch TJ. Antibiotic resistance. Dent Clin N Am. 2003;47: 623-639.

42. Longman LP, Martin MV. The use of antibiotics in the prevention of postoperative infection: a re-appraisal. Br Dent J. 1991;170:257-262.

43. Thomas DW, Hill CM. An audit of antibiotic prescribing in third molar surgery. Br J Oral Maxillofac Surg. 1997;35(2):126-128.

44. Kaczmarzyk T, Wichlinski J, Stypulkowska J, Zaleska M, Panas M, Woron J. Single-dose and multi-dose clindamycin therapy fails to demonstrate efficacy in preventing infectious and inflammatory complications in third molar surgery. Int J Oral Maxillofac Surg. 2007;36(5):417-422.

45. Bergdahl M, Hedström L. Metronidazole for the prevention of dry socket after removal of partially impacted mandibular third molar: a andomized controlled trial. Br J Oral Maxillofac Surg. 2004;42(6):555-558.

46. Lawler B, Sambrook PJ, Goss AN. Antibiotic prophylaxis for dentoalveolar surgery: is it indicated? Aust Dent J. 2005;50 Suppl 2:S54-S59.

47. Gould FK, Elliott TS, Foweraker J, et al. Guidelines for the prevention of endocarditis: report of the Working Party of the British Society for Antimicrobial Chemotherapy. J Antimicrob Chemother. 2006;57(6):1035-1042.

48. Wilson W, Taubert KA, Gewitz M, et al. Prevention of infective endocarditis: guidelines from the American Heart Association: a guideline from the American Heart Association Rheumatic Fever, Endocarditis, and Kawasaki Disease Committee, Council on Cardiovascular Disease in the Young, and the Council on Clinical Cardiology, Council on Cardiovascular Surgery and Anesthesia, and the Quality of Care and Outcomes Research Interdisciplinary Working Group. Circulation. 2007;116(15):1736-1754.

49. NICE. Prophylaxis against infective ednocarditis: antimicrobial prophylaxis against infective endocarditis in adults and children undergoing interventional procedures. Nice Clinical Guidelines No. 64. London: National Institute for Health and Clinical Excellence; 2008.
50. British National Formulary website. http://bnf.org/bnf/bnf/current/3724. htm. Accessed Feb 22, 2010.

51. British National Formulary website. http://bnf.org/bnf/bnf/current/3737. htm. Accessed Feb 22, 2010.

52. British National Formulary website. http://bnf.org/bnf/bnf/current $/ 3863$ htm. Accessed Feb 22, 2010.

53. British National Formulary website. http://bnf.org/bnf/bnf/current/3932. htm. Accessed Feb 22, 2010.

54. Lewis MA, Parkhurst CL, Douglas CW, et al. Prevalence of penicillin resistant bacteria in acute suppurative oral infection. $J$ Antimicrob Chemother. 1995;35:785-791.

55. Baumgartner JC, Xia T. Antibiotic susceptibility of bacteria associated with endodontic abscesses. $J$ Endod. 2003;29:44-47.

56. Trexler MF, Fraser TG, Jones MP. Fulminant pseudomembranous colitis caused by clindamycin phosphate vaginal cream. Am J Gastroenterol. 1997;92(11):2112-2113.

57. Parry MF, Rha CK. Pseudomembranous colitis caused by topical clindamycin phosphate. Arch Dermatol. 1986;122(5):583-584.

58. Surawicz CM. Antibiotic-associated diarrhea and pseudomembranous colitis: are they less common with poorly absorbed antimicrobials? Chemotherapy. 2005;51 Suppl 1:81-89.

59. Clark BM, Homeyer D, Glass KR, D'Avignon LC. Clindamycin-induced Sweet's syndrome. Pharmacotherapy. 2007;27(9):1343-1346.

60. Bubalo JS, Blasdel CS, Bearden DT. Neutropenia after singledose clindamycin for dental prophylaxis. Pharmacotherapy. 2003; 23(1):101-103.

61. Al-Azzam SI, Al-Husein BA, Alzoubi F, Masadeh MM, Al-Horani MA. Self-medication with antibiotics in Jordanian population. Int J Occup Med Environ Health. 2007;20(4):373-380.

62. Awad AI, Eltayeb IB. Self-medication practices with antibiotics and antimalarials among Sudanese undergraduate university students. Ann Pharmacother. 2007;41(7):1249-1255.

63. Yousef AM, Al-Bakri AG, Bustanji Y, Wazaify M. Self-medication patterns in Amman, Jordan. Pharm World Sci. 2008;30(1):24-30.

64. Naji L, Shakhatreh F, Shehabi A. Antibiotic self-medication among health professional students at Jordan University Hospital. MSc thesis, Faculty of Graduate studies, 2007. The University of Jordan, Amman, Jordan.

65. Grigoryan L, Haaijer-Rysjamp FM, Burgerhof JG, et al. Selfmedication with antimicrobial drugs in Europe. Emerg Infect Dis. 2006;12(3):452-459.

66. V"a"an"anen MH, Pietil"a K, Airaksinen M. Self-medication with antibiotics - does it really happen in Europe? Health Policy. 2006;77:166-171.
Therapeutics and Clinical Risk Management

\section{Publish your work in this journal}

Therapeutics and Clinical Risk Management is an international, peerreviewed journal of clinical therapeutics and risk management, focusing on concise rapid reporting of clinical studies in all therapeutic areas, outcomes, safety, and programs for the effective, safe, and sustained use of medicines. This journal is indexed on PubMed Central, CAS,

\section{Dovepress}

EMBase, Scopus and the Elsevier Bibliographic databases. The manuscript management system is completely online and includes a very quick and fair peer-review system, which is all easy to use. Visit http://www.dovepress.com/testimonials.php to read real quotes from published authors. 